\title{
Activation of Signaling Cascades by Weak Extremely Low Frequency Electromagnetic Fields
}

\author{
Einat Kapri-Pardes ${ }^{\mathrm{a}}$ Tamar Hanoch ${ }^{\mathrm{a}}$ Galia Maik-Rachline ${ }^{\mathrm{a}}$ Manuel Murbach ${ }^{\mathrm{b}}$ \\ Patricia L. Bounds ${ }^{\mathrm{b}}$ Niels Kuster ${ }^{\mathrm{b}, \mathrm{c}}$ Rony Seger ${ }^{\mathrm{a}}$ \\ aDepartment of Biological Regulation, the Weizmann Institute of Science, Rehovot, Israel; \\ ${ }^{b}$ Foundation for Research on Information Technologies in Society (IT'IS), Zurich, Switzerland 'Swiss \\ Federal Institute of Technology (ETH) Zurich, Zurich, Switzerland
}

\section{Key Words}

Extremely low frequency magnetic fields $\cdot$ ELF-MF • Mitogen-activated protein kinases - MAPK

- ERK • NADH oxidase

\begin{abstract}
Background/Aims: Results from recent studies suggest that extremely low frequency magnetic fields (ELF-MF) interfere with intracellular signaling pathways related to proliferative control. The mitogen-activated protein kinases (MAPKs), central signaling components that regulate essentially all stimulated cellular processes, include the extracellular signal-regulated kinases $1 / 2$ (ERK1/2) that are extremely sensitive to extracellular cues. Anti-phospho-ERK antibodies serve as a readout for ERK1/2 activation and are able to detect minute changes in ERK stimulation. The objective of this study was to explore whether activation of ERK1/2 and other signaling cascades can be used as a readout for responses of a variety of cell types, both transformed and non-transformed, to ELF-MF. Methods: We applied ELF-MF at various field strengths and time periods to eight different cell types with an exposure system housed in a tissue culture incubator and followed the phosphorylation of MAPKs and Akt by western blotting. Results: We found that the phosphorylation of ERK1/2 is increased in response to ELF-MF. However, the phosphorylation of ERK1/2 is likely too low to induce ELFMF-dependent proliferation or oncogenic transformation. The p38 MAPK was very slightly phosphorylated, but JNK or Akt were not. The effect on ERK1/2 was detected for exposures to ELF-MF strengths as low as $0.15 \mu \mathrm{T}$ and was maximal at $\sim 10 \mu \mathrm{T}$. We also show that ERK1/2 phosphorylation is blocked by the flavoprotein inhibitor diphenyleneiodonium, indicating that the response to ELF-MF may be exerted via NADP oxidase similar to the phosphorylation of ERK1/2 in response to microwave radiation. Conclusions: Our results further indicate that cells are responsive to ELF-MF at field strengths much lower than previously suspected and that the effect may be mediated by NADP oxidase. However, the small increase in ERK1/2 phosphorylation is probably insufficient to affect proliferation and oncogenic transformation. Therefore, the results cannot be regarded as proof of the involvement of ELF-MF in cancer in general or childhood leukemia in particular.

N. Kuster and R. Seger contributed equally to this work.




\section{Cellular Physiology Cell Physiol Biochem 2017;43:1533-1546

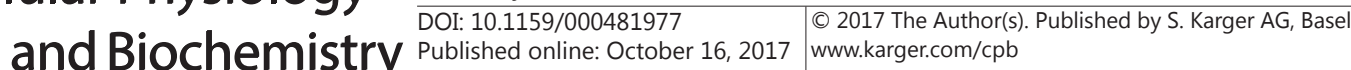 \\ Kapri-Pardes et al.: ERK1/2 Activation by ELF-MF}

\section{Introduction}

Extremely low frequency magnetic fields (ELF-MF) have been classified as possibly carcinogenic to humans based on consistent epidemiological data for childhood leukemia [1-6]. However, ELF-MF cannot traverse membranes or cause DNA damage [7], and the molecular mechanisms underlying the pathogenic effects are not yet understood. Despite earlier controversies, the scientific evidence suggests that ELF-MF influence human cells directly and can induce various effects, such as enhanced proliferation [8-11], adipogenesis of human mesenchymal stem cells [12], angiogenesis [13], and even apoptosis [14]. One mechanism that has been considered in recent years - the activation of signaling processes is attractive because it supports the concept of amplification of the response to a low-energy interaction [15]. Indeed, studies in cellular models show that ELF-MF affect membranal protein distribution [16] and phosphorylation [17]; these effects are then further transmitted via intracellular signaling pathways, which - depending on the cell type - can stimulate transcription and translation, thereby inducing various cellular processes. Given that many signal transducers are involved in the process of tumor development, it is reasonable to assume that effects of ELF-MF might modulate malignancy in cells [18].

The amplification, as well as the rapid and robust nature of intracellular signaling, makes it easier to detect downstream-activated signaling components than the initial interaction. Indeed, several signaling components are activated by short-term (up to $2 \mathrm{~h}$ ) ELF-MF exposure, one of which is an increase in tyrosine (Tyr) phosphorylation. For example, exposure of B-cells at $60 \mathrm{~Hz}$ and 1 Gauss $(0.1 \mathrm{mT})$ for $1-30$ min caused activation of protein Tyr kinase Lyn, as well as of the serine/threonine kinase protein kinase C (PKC) [19]. Similarly, $5 \mathrm{~min}$ exposure at $50 \mathrm{~Hz}$ and $0.10 \mathrm{mT}$ resulted in activation of the protein Tyr kinase Lck, followed by T-cell receptor complexation in Jurkat cell lines [20]. This effect was detected also in adherent cells, as exposure at $50 \mathrm{~Hz}$ and $0.4 \mathrm{mT}$ for $5 \mathrm{~min}$ induced clustering of epidermal growth factor receptors and activation of Ras GTPases in Chinese hamster lung (CHL) fibroblasts [21]. Other signaling pathways that are activated by short-term ELFMF include cyclic AMP/protein kinase A (cAMP/PKA) in human skin fibroblasts exposed to $20 \mathrm{~Hz}$ and $7-8 \mathrm{mT}$ radiation for $60 \mathrm{~min}$ [22], as well as in rat cerebellar granule cells exposed to $60 \mathrm{~Hz}$ and $1 \mathrm{mT}$ for $10-90 \mathrm{~min}$ [23]. Another important signaling mechanism that appears to be influenced by ELF-MF is the elevation of intracellular $\mathrm{Ca}^{2+}$ in exposed cells $[24,25]$ within $1 \mathrm{~min}$ of exposure to ELF-MF at $50 \mathrm{~Hz}$ and $0.1 \mathrm{mT}$. Interestingly, the calcium response, as well as other signaling processes, is elevated upon long-term ( $>3 \mathrm{~h}$ ) ELF-MF exposure as well [26-28], but these effects are due to downstream processes rather than to a direct effect of the radiation [29].

The mitogen-activated protein kinase (MAPK) cascades are an important set of signaling pathways that are activated in response to ELF-MF in most systems examined [29]. The MAPK cascades are central signaling pathways that regulate essentially all stimulated cellular processes, including proliferation, differentiation, apoptosis, and stress response. The four mammalian MAPK cascades are the extracellular signal regulated kinase 1 and 2 (ERK1/2), the c-Jun N-terminal kinase (JNK), p38, and ERK5 [29, 30]. These cascades operate by sequential activation of protein kinases in each layer of the cascade, which eventually leads to phosphorylation of hundreds of substrates that induce and regulate the relevant cellular processes. Another signaling molecule with responses and functions similar to those of the MAPKs is Akt [31]. This protein kinase is activated upon extracellular stimulation by a complex mechanism that involves recruitment to PI3K-phosphorylated phospholipids, followed by phosphorylation of its two activatory residues. As with the MAPKs, the active Akt phosphorylates a large number of substrates to allow the induction and regulation of its responsive processes. Dysregulation of these five signaling pathways is involved in the induction and maintenance of many pathologies, including cancer, diabetes, and autoimmunity [18, 32]. Importantly, the activation of the MAPKs and Akt by both shortterm and long-term exposure to ELF-MF has been demonstrated [33, 34]. Effects of ERKs and Akt due to short-term (30 min) exposures have been found in various systems, including 
HL-60, MCF7, 3Y1, HTB124, HaCaT, and NB69 cells [33-36]. Activatory phosphorylation of stress-related MAPKs, JNK, and p38 by ELF-MF has been demonstrated as well in CHL cells exposed to $50 \mathrm{~Hz}$ for 3 - $15 \mathrm{~min}$ [37-39], and in NB69 cells exposed to $50 \mathrm{~Hz}$ ELF-MF for 15, 30 , or $60 \mathrm{~min}$ [33]. Although production of reactive oxygen species (ROS) [40] or aggregation of receptors [21] has been implicated in the ELF-MF response, the mechanisms by which exposure to ELF-MF is sensed by cells to induce MAPK activation remains unclear.

Generally, the effects of ELF-MF on MAPK and Akt response have been studied with exposures to relatively high field strengths $(>100 \mu \mathrm{T})$ and without consideration of a potential dose-response relationship. To date, no quantitative comparison of cells regarding responses to ELF-MF is available, and the nature of the ELF-MF sensing machinery upstream from the signaling pathways has not been identified. Since the antibodies (Abs) to phosphorylated ERK1/2 previously developed by Seger and co-workers [41] are extremely sensitive to small changes of ERK1/2 activity upon stimulation [42], we used these and other Abs as readouts for exposure to radiation in several cell types. We set out to examine whether cells respond to low ELF-MF using ERK1/2 and other signaling cascades as a readout in a variety of transformed and non-transformed cell lines across broad range of MF strengths. Our results show that all cell lines respond to ELF-MF of varying magnitudes, but the effects on transformed cells is generally lower than those on non-transformed cells; in MDA-MB-231 cells, phosphorylation of ERK1/2 was even decreased upon exposure. Unexpectedly, we found that cells can sense ELF-MF at strengths much lower than was previously thought, as low as $0.15 \mu \mathrm{T}$, and that this ELF-MF sensing involves, at least in part, activation of NADH oxidase. No effect on physiological activities was detected, and therefore, the results cannot be regarded as proof of the involvement of ELF-MF in cancer in general or childhood leukemia in particular.

\section{Materials and Methods}

\section{Antibodies and reagents}

Tetradecanoyl phorbol acetate (TPA), 4',6-diamino-2-phenylindole (DAPI), diphenyleneiodonium (DPI), bovine serum albumin (BSA), as well as Abs to doubly phosphorylated ERK1/2 (pERK), general ERK (gERK), doubly phosphorylated JNK (pJNK), doubly phosphorylated p38 (pp38), phosphorylated Akt (pSer473-Akt; (pAkt)), and general Akt were all obtained from Sigma Israel (Rehovot, Israel). Secondary mouse Abs conjugated to horseradish peroxidase (HRP) as well as secondary light-chain-specific HRP conjugated secondary Abs were purchased from Jackson ImmunoResearch (West Grove, PA USA). Western blots were developed with the enhanced chemoiluminesence (ECL) system purchased from Amersham Biosciences (Piscataway, USA). Growth media and fetal calf serum (FCS) were obtained from Gibco (ThermoFisher Scientific, Waltham, MA USA). Nitrocellulose membranes were from Tamar (Jerusalem, Israel).

\section{Cell culture growth and harvesting}

The following cell lines were investigated: immortalized COS7, CHO, HB2, and MEF as well as transformed MDA-MB-231 (MDA), HeLa, and PC3, cell lines - grown on tissue culture plates - and transformed Jurkat and REH cell lines - grown in flasks - all with medium according to supplier instructions. For the experiments, the cells were serum-starved for $16 \mathrm{~h}$ prior to stimulation in medium containing $0.1 \%$ FCS. After the exposure, adherent cells were washed with phosphate-buffered saline (PBS), while the Jurkat and RHE cells were centrifuged $\left(5,000 \times \mathrm{g}, 10 \mathrm{~min}, 4^{\circ} \mathrm{C}\right)$ and washed once with PBS. Cells were then lysed with RIPA buffer, consisting of $20 \mathrm{mM}$ Tris/HCl (pH 7.4), $137 \mathrm{mM} \mathrm{NaCl}, 10 \%(\mathrm{v} / \mathrm{v})$ glycerol, $1 \%$ Triton X-100, $0.5 \%$ sodium deoxycholate, $0.1 \%$ sodium dodecyl sulfate (SDS), $2 \mathrm{mM}$ EDTA, $1 \mathrm{mM}$ phenylmethylsulfonyl fluoride (PMSF), and $20 \mu \mathrm{M}$ leupeptin, for $10 \mathrm{~min}$ on ice, followed by centrifugation (15 $\mathrm{min}$ at 20, $000 \times \mathrm{g}$, $4^{\circ} \mathrm{C}$ ) to sediment the non-soluble components. The supernatants were collected, boiled in protein sample buffer and subjected to SDS polyacrylamide gel electrophoresis (SDS-PAGE) followed by transfer onto nitrocellulose membranes by electroblotting.

Western blotting for detection of proteins and protein phosphorylations

To detect the phosphorylation of the MAPKs, we used the very sensitive pERK Abs to doubly phosphorylated ERK1/2 [41]. To detect changes in phosphorylation, we compared the results of labeling with 


\section{Cellular Physiology Cell Physiol Biochem 2017;43:1533-1546 \begin{tabular}{ll|l} 
DOI: 10.1159/000481977 & $\begin{array}{l}\text { O } 2017 \text { The Author(s). Published by S. Karger AG, Basel } \\
\text { www.karger.com/cpb }\end{array}$ \\
\hline and Biochemistry
\end{tabular} \\ Kapri-Pardes et al.: ERK1/2 Activation by ELF-MF}

pERK to those obtained from labeling with gERK, to verify that the level of phosphorylation and not protein expression was changed upon stimulation. The blotted membranes were incubated with the corresponding primary Abs ( $60 \mathrm{~min}, 23^{\circ} \mathrm{C}$ ), followed by washes and incubation with HRP-conjugated secondary Abs. Blots were developed with ECL and processed with a ChemiDoc imaging system (BioRad, Hercules, CA USA). Each experiment was performed at least three times. Quantification of the band intensities was performed with the BioRad Image Lab ${ }^{\mathrm{TM}}$ Software analysis tool.

In vitro exposure system

Exposures were performed with the sXcELF ELF-MF in vitro exposure system [43] developed by the IT'IS Foundation (Zurich, Switzerland), which is comprised of two identical exposure chambers - for active and sham exposures. They were installed in a commercial $\mathrm{CO}_{2}$ incubator (Heracell 240i, ThermoFisher Scientific, Waltham MA, USA). The ELF-MF strengths delivered to the exposure and sham chambers differ by a factor of at least $140(>43 \mathrm{~dB})$, which was achieved through passive mu-metal shielding. Since it was hypothesized that the crosstalk of the exposure chamber to the sham chamber was sufficient to be biologically effective, the circuitry of the system was redesigned to allow application of low field strengths $(<0.1 \mu \mathrm{T})$. For field strengths above $20 \mu \mathrm{T}$, identical currents were present in the sham chamber, but with the dual-winded coils turned in the opposite direction to generate the same thermal load ( $1 \mathrm{~W}$ at $1 \mathrm{mT})$ without generation of any ELF-MF. For field strengths below $20 \mu \mathrm{T}$, any generation of heat by the coil can be neglected $(<1 \mathrm{~mW})$. The two chambers were mechanically coupled, such that any vibration would be present in both chambers, and the samples were placed on a dish-holder that was standing directly on the incubator-shelf on feet extending through four holes in the bottoms of the chambers. Thus, there were no differences in acoustic or vibrational exposure between the exposure and sham chambers. The exposure system was computer controlled for automated and continuous generation and monitoring of coil currents, chamber temperatures, and fan speeds.

\section{Exposure of cells to ELF-MF}

Cells grown in $6 \mathrm{~cm}$ petri dishes to $60-70 \%$ subconfluence or in $13 \mathrm{ml}$ tubes containing $6 \times 10^{6}$ cells in suspension were exposed to ELF-MF in the sXcELF exposure system inside the $\mathrm{CO}_{2}$ incubator at $37^{\circ} \mathrm{C}$. For the results shown in Fig. 1 and 2, exposures of cells in the chambers were performed with $50 \mathrm{~Hz}$ pure signal in on/off intervals of $5 \mathrm{~min} / 1 \mathrm{~min}$ for the indicated times, with the plates or tubes at zero time $\left(T_{0}\right)$ as the negative controls, and the TPA-treated positive controls placed inside the incubator but not inside the chambers. The dose-response experiments shown in Fig. 3 and 4 were performed with time intervals of 5, 15 , and $45 \mathrm{~min}$ at the indicated field strengths, with the $T_{0}$ and TPA controls placed in the incubator. After exposures, the cells were harvested as described above. No detectible changes in the temperature of the cell culture media were observed during the application of $1 \mathrm{mT}$ ELF-MF for up to $90 \mathrm{~min}$ in this system.

Immunofluorescence microscopy

Cells were fixed on slides in 3\% paraformaldehyde in PBS for $20 \mathrm{~min}$ at $23^{\circ} \mathrm{C}$ as previously described [44], followed by incubation with $2 \%$ BSA in PBS $\left(15 \mathrm{~min}, 23^{\circ} \mathrm{C}\right)$ and permeabilization with $0.1 \%$ Triton $\mathrm{X}-100$ in PBS $\left(5 \mathrm{~min}, 23^{\circ} \mathrm{C}\right)$. The fixed cells were then incubated with the appropriate primary Abs $(1 \mathrm{~h}$, $23^{\circ} \mathrm{C}$ ), washed three times with PBS, then incubated with rhodamine-conjugated secondary Ab for $1 \mathrm{~h}$ at $23^{\circ} \mathrm{C}$ and treated with $0.5 \mu \mathrm{M}$ DAPI. Cells were visualized at $60 \times$ magnification with a spinning-disk confocal microscope (Zeiss, Jena, Germany). Background correction and contrast adjustment of raw data images were performed with Adobe Photoshop (San Jose, CA USA).

\section{Inhibition of signaling response by DPI}

COS7 and HeLa cells were exposed to ELF-MF at $50 \mathrm{~Hz}$ and $1 \mathrm{mT}$ for $30 \mathrm{~min}$ in the absence and presence of pretreatment for $20 \mathrm{~min}$ with $10 \mu \mathrm{M}$ DPI. Cells were harvested and analyzed, and the western blots were quantified.

\section{Statistical analysis}

Statistical analysis data are expressed as the mean \pm the standard error of the mean (SEM) from three or five repeats. Statistical evaluations were carried out by means of functional analysis and the Student's $t$-test (two-tailed) to test for differences between the control and experimental results. Values of $\mathrm{P}<0.05$ were considered statistically significant. The statistical analysis of the imagStream data, expressed as mean \pm SEM, was carried out with Student's $t$-test as described above. 


\section{Results}

\section{Effects of ELF-MF on MAPKs in different cell lines}

To examine whether all cells respond equally to ELF-MF and whether the response is dependent on oncogenicity, we exposed transformed and non-transformed cells to ELF$\mathrm{MF}$ and followed the changes in levels of phosphorylated ERK1/2. The exposures were performed with $50 \mathrm{~Hz}$ and $1 \mathrm{mT}$, with sham exposures of $\sim 7 \mu \mathrm{T}(<43 \mathrm{~dB})$, with on/off intervals of $5 \mathrm{~min} / 1 \mathrm{~min}$, as initial experiments indicated an enhanced sensitivity for on/ off exposures. Plates that were used as negative $\left(T_{0}\right)$ and positive (TPA-treated) exposure controls were placed inside the incubator, outside of the exposure chambers. Each of the experiments reported here was reproduced at least three times. In all non-transformed immobilized cells (CHO, MEF, HB2, and COS7), we detected 4-8-fold elevations in ERK phosphorylation already 5 min into the exposure regimen (Fig. 1A). This activity remained high for up to $71 \mathrm{~min}$, indicating sustained, rather than transient, elevation, which might have distinct effects on transcription [42]. In COS7 and MEF cells, the elevation was much

Fig. 1. Time course of ERK1/2 phosphorylation upon ELF-MF exposure in different cell lines. (A). ERK1/2 phosphorylation in nontransformed cells. The indicated cell lines were exposed to ELF-MF at $50 \mathrm{~Hz}$ pure signal and $1 \mathrm{mT}$ or $7 \mu \mathrm{T}$ in separate but identical chambers with on/off intervals of 5/1 min. Incubation with TPA at $250 \mathrm{nM}$ for 15 min served as a positive control for ERK1/2 activation; the level of stimulation at $T_{0}$ was taken as the negative control. Cells were harvested, washed, and lysed, and lysates were analyzed by SDS-PAGE and western blot with appropriate Abs. (B) Quantification of the results shown in A. The intensity of the ERK1/2 bands was quantified as described under Materials and Methods. Fold increase was calculated relative to the level of phosphorylation at $\mathrm{T}_{0}$. The graphs represent the averages and standard errors of either five (COS7 and $\mathrm{CHO}$ ) or three (MEF and HB2) distinct experiments. (C) ERK1/2 phosphorylation in transformed cells. The indicated cell lines were treated and blotted as outlined in A. MDA stands for MDA-MB-231 cells. (D) Quantification of the results shown in A. The intensity of the ERK1/2 bands was quantified as described under Materials and Methods. Fold increase was calculated relative to the level of phosphorylation at $T_{0}$. The graphs represent the averages and standard errors of either 5 (HeLa, Jurkat, and CHO) or 3 (PC3 and MDA) distinct experiments.

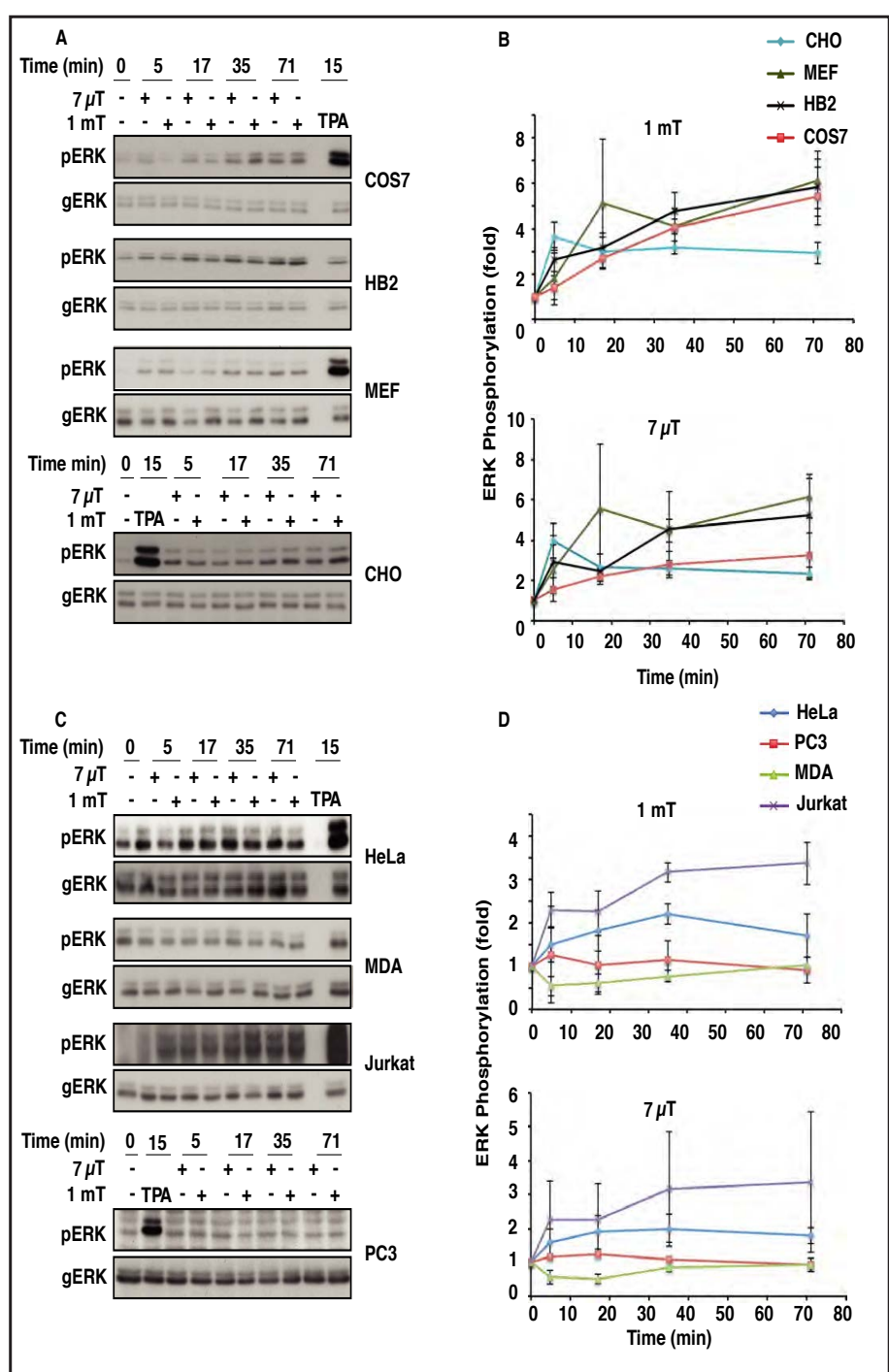


Fig. 2. Screening for phosphorylation of ERK1/2, JNK, p38, and Akt upon exposure to ELF-MF. (A) Exposure effects on the phosphorylation of $\mathrm{p} 38$, JNK, and Akt. COS7, HB2, and HeLa cells were exposed to ELF-MF for the indicated times, then harvested and analyzed by western blot with the indicated Abs. (B) Quantification of the results of COS7 cells. The intensity of the ERK1/2, JNK, p38, and Akt bands in the COS7 experiments was quantified as described under Materials and Methods. Fold increase was calculated relative to the level of phosphorylation at $T_{0}$. The graphs represent the averages and standard errors of four distinct experiments.

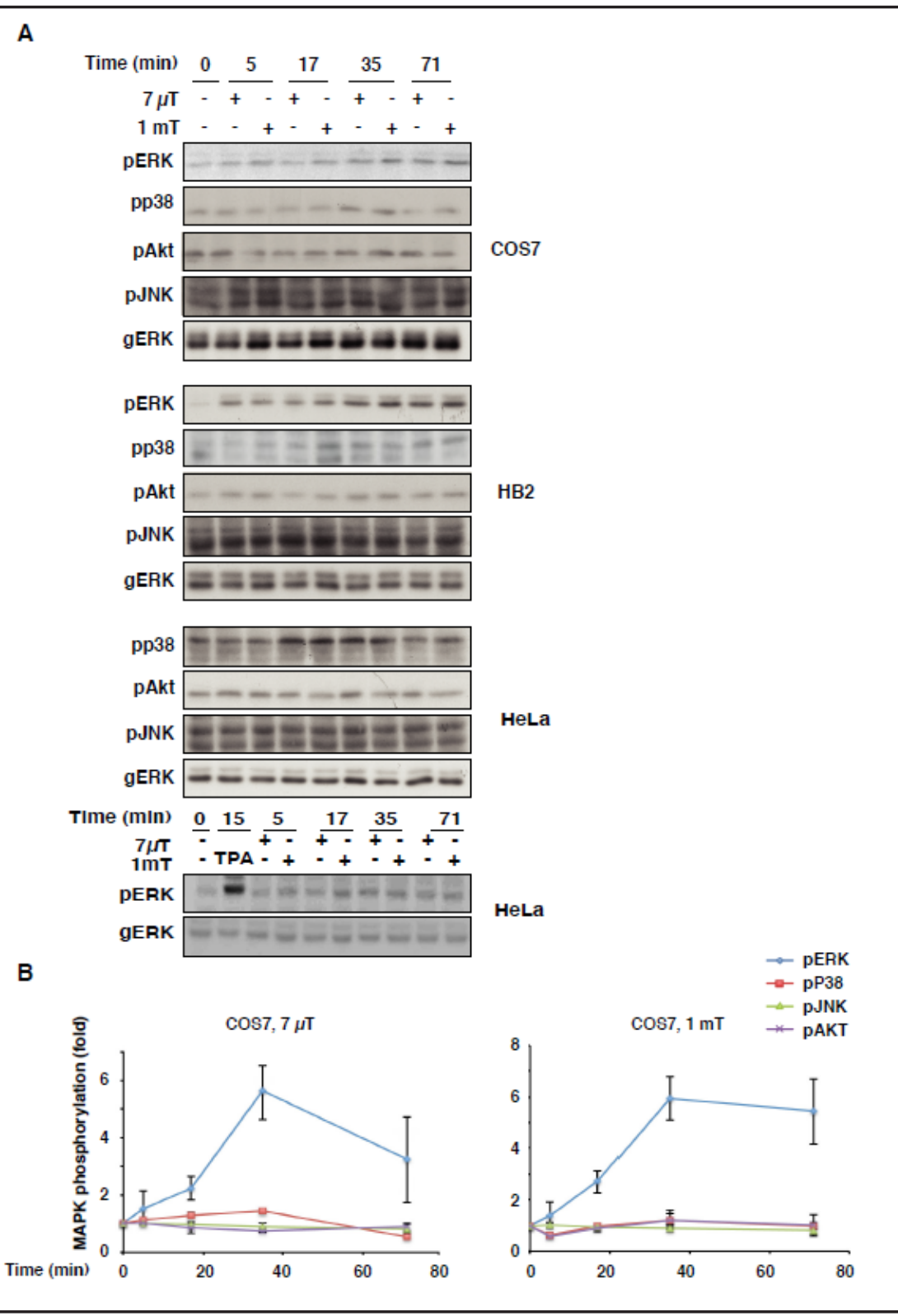

lower than that of TPA, while in HB2 and CHO cells, which respond poorly to TPA, the effect was similar to the low TPA effect. Unlike the consistent effects in the immortalized cells, the effects in transformed cells were more variable (Fig. 1B). In Jurkat and HeLa cells, ERK1/2 phosphorylation exhibited 2 - 3-fold increases at $5 \mathrm{~min}$, which was slightly elevated up to 60 min after stimulation. The effect on PC3 cells was marginal, and, in MDA-231-MB cells, ERK1/2 phosphorylation was slightly decreased by the radiation. Taken together, these results indicate that all cells can respond to ELF-MF by modulating ERK1/2 phosphorylation. However, in all cells, the effect was too small to be likely to influence proliferation or carcinogenesis. The effect in cancer cells was much lower than that in non-transformed cells, and, in MDA-MB-231 cells, was even negative. The overall lower phosphorylation induced by ELF-MF in cancer cells is probably due to high expression of negative regulators of ERK1/2, such as MAPK phosphatases (MKPs [45]), which are likely to be involved also in the reduction of ERK1/2 phosphorylation in MDA-MB-231. No effect was detected on cell proliferation cell morphology or cell death (data not shown).

\section{KARGER}


Fig. 3. Time and strength response of ERK1/2 phosphorylation to ELF-MF. (A) ERK1/2 phosphorylation in COS7 cells. The cells were exposed to $50 \mathrm{~Hz}$ ELF-MF at the field strengths and times indicated. Cells were then harvested, analyzed, and the western blots were developed with the indicated Abs as described above. (B) Quantification of the results shown in $A$. The graphs represent the averages and standard errors from three distinct experiments (see Materials and Methods). (C) ELF-MF strength response of COS7 cells. The cells were exposed to $50 \mathrm{~Hz}$ ELF-MF for $15 \mathrm{~min}$ at the field strengths indicated. Cells were then harvested, analyzed, and the western blots were developed with the indicated Abs as described above. (D) Quantification of the results shown in C. The graphs represent the averages and standard errors from three distinct experiments (*: p <0.01; **: p<0.05). (E) ERK1/2 phosphoryla-

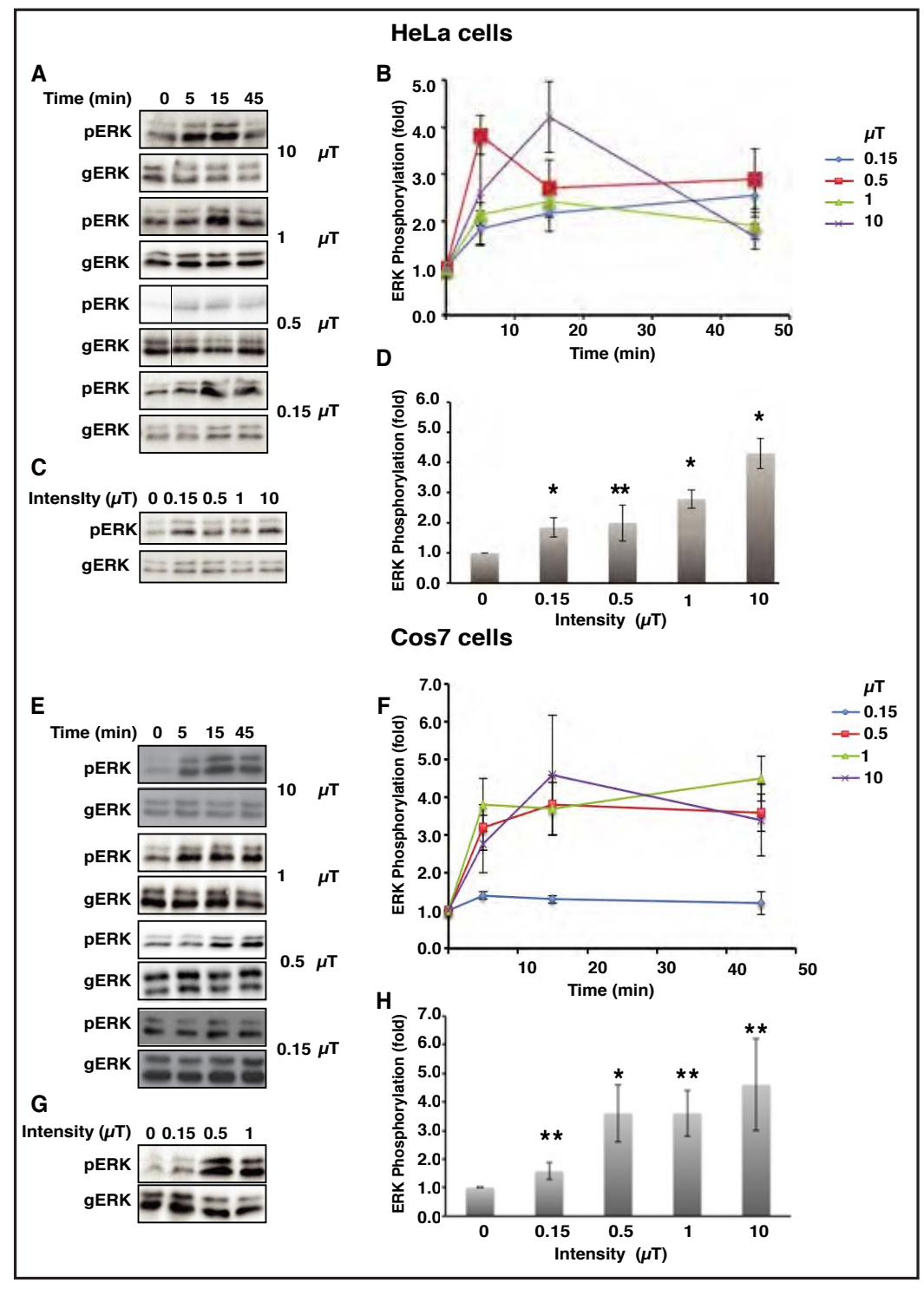

tion in HeLa cells. The cells were exposed to $50 \mathrm{~Hz}$ ELF-MF at the field strengths and times indicated. Cells were then harvested, analyzed, and the western blots were developed with the indicated Abs as described above. (F) Quantification of the results shown in E. The graphs represent the averages and standard errors from three distinct experiments. (G) ELF-MF strength response of HeLa cells. The cells were exposed to $50 \mathrm{~Hz}$ ELF-MF for $15 \mathrm{~min}$ at the field strengths indicated. Cells were then harvested, analyzed, and the western blots were developed with the indicated Abs as described above. $(\mathrm{H})$ Quantification of the results shown in $\mathrm{G}$. The graphs represent the averages and standard errors from three distinct experiments $(*: p$ $<0.01 ; * *$ : $<0.05)$.

Three of the cell lines (HB2, COS7, and HeLa) were also screened for activatory phosphorylation of p38, JNK, and Akt (Fig. 2). No significant change in the phosphorylation of JNK or Akt was detected in any of the cell lines for any of the conditions examined. On the other hand, the phosphorylation of p38 was slightly affected upon exposure. In COS7 cells, marginal changes in phosphorylation were maximal (1.3 fold, Fig. $2 \mathrm{~B}$ ) at $35 \mathrm{~min}$. In HeLa cells, the peak phosphorylation was slightly higher (1.4 fold) and occurred at 17 35 min. Interestingly, in HB2 cells, the changes were small but more complex, in that in 
A
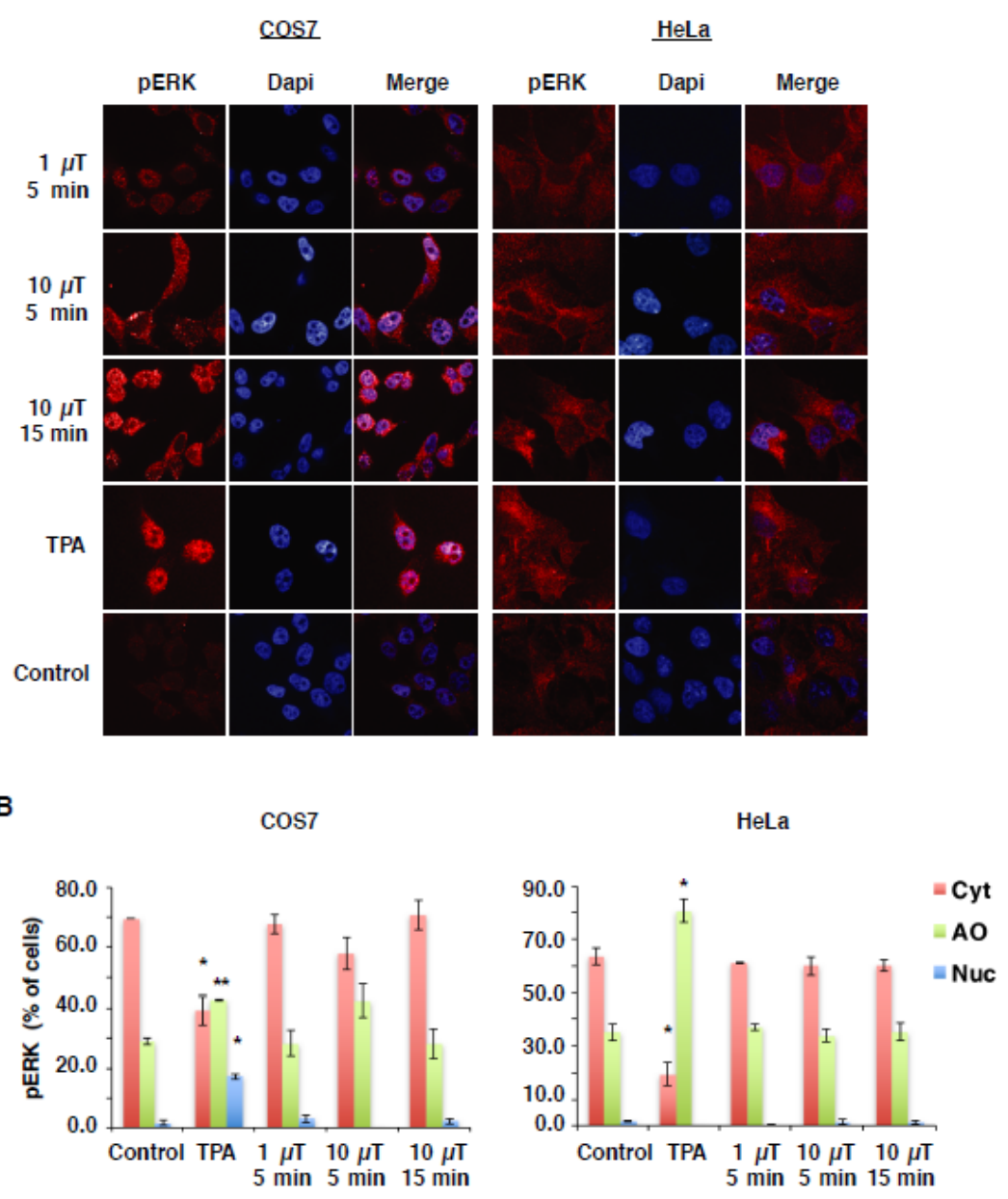

Fig. 4. Fluorescence micrographs showing distribution of phosphorylated ERK1/2 in COS7 and HeLa cells after ELF-MF exposure. (A) Fluorescence micrographs of phosphorylated ERK1/2. COS7 and HeLa cells were grown on slides and exposed to $50 \mathrm{~Hz}$ ELF-MF at the indicated times and field strengths. Incubation with TPA at $250 \mathrm{nM}$ for $15 \mathrm{~min}$ (TPA) or non-treated cells (Control) served as positive and negative controls, respectively. Cells were fixed and stained with pERK and DAPI, followed by visualization with a fluorescence microscope. (B) Quantification of pERK in different localizations, the graphs represent the number of relative events of fluorescence signals detected in the cytosol (Cyt), nucleus (Nuc), and all over the cell (AO). The percent of pERK was calculated relative to total cells (visualized with DAPI staining) taken from three fields of $40-60$ cells each from two independent experiments, as described under Material and Methods $\left(*: \mathrm{p}<0.01{ }^{* *}: \mathrm{p}<0.05\right)$.

these cells, a small amount of phosphorylated p38 $\beta$ was detected, which first decreased, then increased almost to the initial level of phosphorylation at $17 \mathrm{~min}$, and then decreased again. The minor basal level of phosphorylation of P38 $\alpha$ was elevated by exposure, reaching a maximum ( 2.5 fold) at $17 \mathrm{~min}$, and decreased thereafter. However, the overall level of p38 phosphorylation was increased (2.2-fold) $17 \mathrm{~min}$ after exposure, indicating that, in all cell types, p38 phosphorylation is only slightly affected.

\section{Response of ERK1/2 to different ELF-MF strengths}

The observation that enhanced levels of phosphorylation of ERK1/2 are very similar for exposures at $1 \mathrm{mT}$ and $\sim 7 \mu \mathrm{T}$ suggests that both field strengths were higher than saturating.

\section{KARGER}




\section{Cellular Physiology Cell Physiol Biochem 2017;43:1533-1546 and Biochemistry DOI: 10.1159/000481977 $20 \begin{aligned} & \text { O } 2017 \text { The Author(s). Published by S. Karger AG, Basel } \\ & \text { wwww.kargercom/cpb }\end{aligned}$ \\ Kapri-Pardes et al.: ERK1/2 Activation by ELF-MF}

Fig. 5. Inhibiton by DPI of ERK1/2 phosphorylation upon ELF-MF exposure. (A) COS7 and HeLa cells were exposed to ELF-MF at $50 \mathrm{~Hz}$ and $1 \mathrm{mT}$ for $30 \mathrm{~min}$ in the absence and presence of pretreatment with $10 \mu \mathrm{M}$ DPI for $20 \mathrm{~min}$. Cells were harvested, washed, and lysed, and the lysates were analyzed by western blotting with the indicated Abs. (B) Quantification of the results in shown in A. The bargraphs represent the averages and standard errors from three independent experiments, as described under Materials and Methods ( $*$ : $\mathrm{p}<0.01)$.

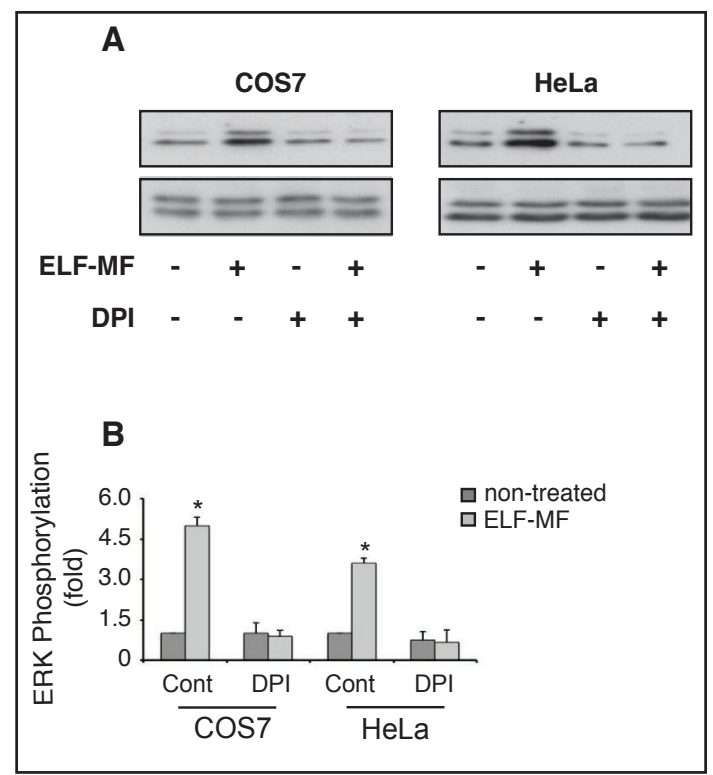

We therefore decided to examine whether exposure to lower EMF-MF strengths could evoke elevated phosphorylation in a dose-dependent manner. For this purpose, we exposed the COS7 and HeLa cell lines to ELF-MF strengths of $0.15,0.5,1$, and $10 \mu \mathrm{T}$ and followed the timedependent phosphorylation of ERK1/2. In these experiments, we found a time-dependent ERK1/2 phosphorylation at all field strengths that peaked after $5-15 \mathrm{~min}$ and, in most cases, was sustained for up to $45 \mathrm{~min}$ (Fig. 3). To better demonstrate the "dose response", we analyzed extracts derived from 15 min exposures at field strengths of $0-10 \mu$ T for ERK1/2 phosphorylation and found that ERK1/2 phosphorylation is stimulated by exposure to ELFMF at strengths as low as $0.15 \mu \mathrm{T}$ in both cell lines (Fig. 3C, D, G, and H). In HeLa cells, the response is elevated by exposure to $10 \mu \mathrm{T}$ to a level similar to that elicited by exposure to $7 \mu \mathrm{T}$ and $1 \mathrm{mT}$ (Fig. 1D). In the case of Cos7 cells, phosphorylation of ERK1/2 plateaus at $1 \mu \mathrm{T}$ at levels similar to the responses to higher strengths exposures. Interestingly, in Jurkat and REH cells, ERK1/2 phosphorylation plateaus for exposures at $10 \mu \mathrm{T}$ (data not shown), similar to the finding in HeLa cells.

\section{Localization of ERK1/2 phosphorylation elicited by exposure to ELF-MF}

The relatively small effect of the ELF-MF on phosphorylation of ERK1/2 raises the possibility that phosphorylation is relatively strongly activated in only a subset of cells, while other cells do not respond at all. Such differential effects in a given cell culture could result from the presence of cells at different stages of the cell cycle, or be due to downregulation of the cascade or to differential expression of components upstream from the cascade in certain cells. To investigate this possibility, as well as to determine the subcellular localization of phosphorylation, we analyzed COS7 and HeLa cells by fluorescence microscopy after exposure to ELF-MF at $1 \mu \mathrm{T}$ for $5 \mathrm{~min}$ and at $10 \mu \mathrm{T}$ for 5 and $15 \mathrm{~min}$, followed by immunostaining with the anti-pERK Abs (Fig. 4A). The bar-graphs show that phosphorylation occurs in all cells of the exposed cultures rather than in only subpopulations of cells. The staining of the cells is independent of MF strength, as similar homogeneous staining was observed in response to the different exposure levels results in different levels of ERK1/2 phosphorylation in the two cell lines. Interestingly, although phosphorylated ERK1/2 generally exhibits a strong tendency to translocate to the nucleus shortly after stimulation [46], the staining upon the ELF-MF exposure was mostly distributed in the cytosol or (much less) all over the cells, in contrast to the TPA, in which case the phosphorylated ERK1/2 was distributed mainly in the nucleus. The very small amount of translocation of phosphorylated ERK1/2 may be a consequence of the weaker ERK1/2 activation. Thus, aside from the small ERK1/2 activation, 


\section{Cellular Physiology Cell Physiol Biochem 2017;43:1533-1546

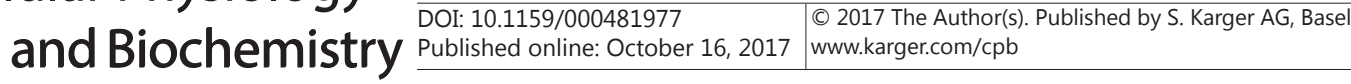 \\ Kapri-Pardes et al.: ERK1/2 Activation by ELF-MF}

the minute translocation can be an additional reason for the lack of physiological effects of the MF exposure.

The mechanism of sensing ELF-MF that induces ERK1/2 phosphorylation

One important question raised by the results is, how do cells sense ELF-MF to induce the ERK1/2 response? In a previous study, the Seger research group showed that microwave radiation is sensed by a membranal NADH oxidase that, in turn, induces the formation of ROS to stimulate EGFR-ERK1/2 signaling [47]. To examine whether NADH oxidase is involved in the mechanism of ERK1/2 phosphorylation upon ELF-MF exposure as well, we tested the response in the presence of the flavoprotein inhibitor diphenyleneiodonium (DPI). Indeed, we found that this inhibitor completely abolishes the ERK phosphorylation response to $1 \mathrm{mT}$ ELF-MF exposure in both cell lines (Fig. 5). Therefore, it is likely that the mechanism of signal reception is similar to that described for microwave radiation. No other short-term effects on cell morphology or viability were observed under any of the conditions used.

\section{Discussion}

A key question in the study of the effects of ELF-MF on living tissues has been whether the low energy of EMF, which cannot transverse the plasma membrane, can at all evoke a response at the cellular level. As described in the introduction, it is now clear that some cells can respond to the low energy of $50-60 \mathrm{~Hz}$ ELF-MF at relatively high field strengths of $>0.1 \mathrm{mT}[19,24,25]$. However, others have failed to detect any effect [48]. Therefore, it became important to examine how general the cellular response to ELF-MF is, at what field strengths it can be detected, and what the mechanism of cellular ELF-MF sensing is. With ERK1/2 phosphorylation as the readout to report cellular responses to ELF-MF, our main findings are that several different cell lines respond to ELF-MF at $50 \mathrm{~Hz}$ even at field strengths of less than $1 \mu \mathrm{T}$. The effect is dependent on cell type, where the ELF-MF effect on ERK1/2 phosphorylation in transformed cells is lower than that in non-transformed cells. In addition, we show that, similar to responses to microwave radiation, the ELF-MF response is likely to be mediated by NADH oxidase, which might serve as the sensor of the magnetic field.

In this study, we undertook to evaluate the responses of a variety of cell lines to exposure to low strength MF, and found that all eight cell lines examined respond to ELF-MF to varying degrees. Interestingly, the effects on the phosphorylation in transformed cells was lower than that of non-transformed ones, and, in MDA-MB-231 cells, the phosphorylation of ERK1/2 even decreased upon exposure. The overall lower phosphorylation induced by ELF-MF in cancer cells is probably due to high expression of negative regulators of the ERK1/2 cascade in these cells, which are part of feedback loops that downregulate ERK1/2 signaling to cause its transient effect. These negative feedback loops include MKPs as well as scaffold proteins [49], and it is clear that they are induced in almost all cancers, particularly those regulated by the Ras and Raf oncogenes. Indeed, in MDA-MB-231, which are Rastransformed, ERK1/2 was inactivated rather than activated upon ELF-MF exposure, possibly because these cells contain very high amounts of MKPs, which can be activated shortly after exposure to induce the transient inactivation observed. Thus, all cell types respond to ELFMF, but the downstream effects on ERK1/2 phosphorylation might vary according to the variable expression of modulating proteins in the different cell types.

We also investigated the minimal MF strength required to induce ERK1/2 activation. We found that all cell types examined are sensitive to ELF-MF at field strengths as low as $\sim 7 \mu \mathrm{T}$. The response of the cells to MF of strength this low - initially intended as the "sham" exposure level in our experiments - was similar to the response to the higher field strength of $1 \mathrm{mT}$. These findings led us to conjecture that both field strengths elicit a saturated response and that cells could likely respond to ELF-MF at much lower strengths, and we designed experiments to examine this hypothesis. We found that cells respond to fields of strength 
as low as $0.15 \mu \mathrm{T}$, which is not much different from the background MF inside an incubator or near a standard electrical socket. Our findings indicate that cells can sense and respond to $\mathrm{MF}$ at strengths far lower $-0.15-10 \mu \mathrm{T}$ - than the much higher levels of $0.1-10 \mathrm{mT}$ generally studied and reported.

We are further interested in the mechanism by which the cells sense low energy magnetic fields. We used DPI - an inhibitor of flavoproteins, e.g., NADH oxidase, that abolishes the signaling response via phosphorylation of ERK1/2 in COS7 and HeLa cells - to show that this protein may be involved in the response to ELF-MF exposure (Fig. 5). The Seger research group has previously reported that NADH oxidase plays a role as a magnetoreceptor for sensing microwave radiation [47]. Mediation by NADH oxidase of the signaling pathway evoked by microwave radiation was reported to be via production of ROS and activation of the epidermal growth factor (EGF) receptor that subsequently induces ERK1/2 phosphorylation. We suggest that the response evoked by ELF-MF is similar to that observed with microwave radiation. Indeed, the EGF receptor has already been shown as an effector of ELF-MF that leads to ERK activation in CHL cells [21]. The ability of NADH oxidase to generate free radicals in response to MF, and its function as an upstream inducer of intracellular signaling, may suggest that this protein plays a role in the cells' ability to sense radiation. However, at this stage, the molecular mechanism that allows cells to sense MF, and whether there might be other proteins that operate separately from or in conjunction with NADH oxidase to sense MF, is still not clear.

The blue-light activated cryptochromes have also been invoked as a potential primary molecular magnetoreceptor for geo-orientation in a variety of species [50]. This family of flavoproteins has also been shown to be inhibited by DPI [51, 52]. We have observed that the response to ELF-MF mediated by the ERK1/2 signaling in COS7 and HeLa cells is sensitive to blue light (unpublished results), and we cannot rule out that the sensitivity to DPI of the ERK1/2 signaling response in COS7 and HeLa cells might be in part due to inhibition of cryptochrome.

It is very difficult to extrapolate conclusions from in vitro studies performed on cell lines to interpret epidemiological findings in human populations. In the ARIMMORA risk assessment [1], in vitro studies were designed to probe mechanisms of interactions of ELF-MF with living tissues. The findings we report here, that the activation of the ERK1/2 intracellular signaling cascade by exposure to ELF-MF is dependent on time and MF at field strengths of less than $1 \mu \mathrm{T}$, are important for guiding future investigations in terms of exposure protocol design and choice of experimental end point. The finding that the ERK1/2 phosphorylation can be mediated at least in part by NADH oxidase is a valuable indication that the mechanism of ELF-MF impact on cells involves oxidative stress pathways.

It is important to note, however, that, although ERK1/2 might be involved in the initiation and progression of proliferation and cancer, the level of phosphorylation of these kinases in response to exposure to ELF-MF at all strengths is too low to induce any physiological or pathological effects by themselves, and our results cannot be regarded as proof of the involvement of ELF-MF in cancer in general or childhood leukemia in particular.

\section{Acknowledgements}

The study was supported by EU grant agreement no. 282891 to the ARIMMORA consortium. R.S. is an incumbent of the Yale S. Lewine and Ella Miller Lewine professorial chair for cancer research.

\section{Disclosure Statement}

The authors declare that there are no conflicts of interest regarding the publication of this paper. 


\section{Cellular Physiology Cell Physiol Biochem 2017;43:1533-1546 \begin{tabular}{l|l|l} 
and Biochemistry Published onlIne: October 16, 2017 & $\begin{array}{l}\text { (c) } 2017 \text { The Author(s). Published by S. Karger AG, Basel } \\
\text { www.karger.com/cpb }\end{array}$ \\
\hline
\end{tabular}}

Kapri-Pardes et al.: ERK1/2 Activation by ELF-MF

\section{References}

1 Schuz J, Dasenbrock C, Ravazzani P, Roosli M, Schar P, Bounds PL, Erdmann F, Borkhardt A, Cobaleda C, Fedrowitz M, Hamnerius Y, Sanchez-Garcia I, Seger R, Schmiegelow K, Ziegelberger G, Capstick M, Manser M, Muller M, Schmid CD, Schurmann D, Struchen B, Kuster N: Extremely low-frequency magnetic fields and risk of childhood leukemia: A risk assessment by the ARIMMORA consortium. Bioelectromagnetics 2016;37:183-189.

-2 Anderson LE, Bailey WH, Blackman CF, Day NE, DelPizzo V, Guénel P, Hansson K, Hatch E, Juutilainen, J, Kheifets LI, Liboff AR, McCormick DL, Mevissen M, Miyakoshi J, Olsen JH, Portier CJ, Saunders RD, Schüz J, Stolwijk JAJ, Stuchly MA, Veyret B: Non-ionizing radiation, Part 1: Static and extremely low-frequency (ELF) electric and magnetic fields. IARC monographs 80 on the evaluation of carcinogenic risks to humans. Lyon France,IARC press,2002.

3 Grellier J, Ravazzani P, Cardis E: Potential health impacts of residential exposures to extremely low frequency magnetic fields in Europe. Environ Int 2014;62:55-63.

4 Repacholi M: Concern that "EMF” magnetic fields from power lines cause cancer. Sci Total Environ 2012;426:454-458.

-5 Cogliano VJ, Baan R, Straif K, Grosse Y, Lauby-Secretan B, El Ghissassi F, Bouvard V, Benbrahim-Tallaa L, Guha N, Freeman C, Galichet L, Wild CP: Preventable exposures associated with human cancers. J Natl Cancer Inst 2011;103:1827-1839.

6 Buffler PA, Kwan ML, Reynolds P, Urayama KY: Environmental and genetic risk factors for childhood leukemia: appraising the evidence. Cancer Invest 2005;23:60-75.

7 Valberg PA, Kavet R, Rafferty CN: Can low-level 50/60 Hz electric and magnetic fields cause biological effects? Radiat Res 1997;148:2-21.

8 Cadossi R, Bersani F, Cossarizza A, Zucchini P, Emilia G, Torelli G, Franceschi C: Lymphocytes and lowfrequency electromagnetic fields. FASEB J 1992;6:2667-2674.

-9 Funk RH, Monsees T, Ozkucur N: Electromagnetic effects - From cell biology to medicine. Prog Histochem Cytochem 2009;43:177-264.

10 Maes A, Verschaeve L: Genetic damage in humans exposed to extremely low-frequency electromagnetic fields. Arch Toxicol 2016;90:2337-2348.

11 Grassi C, D’Ascenzo M, Torsello A, Martinotti G, Wolf F, Cittadini A, Azzena GB: Effects of $50 \mathrm{~Hz}$ electromagnetic fields on voltage-gated $\mathrm{Ca} 2+$ channels and their role in modulation of neuroendocrine cell proliferation and death. Cell Calcium 2004;35:307-315.

12 Du L, Fan H, Miao H, Zhao G, Hou Y: Extremely low frequency magnetic fields inhibit adipogenesis of human mesenchymal stem cells. Bioelectromagnetics 2014;35:519-530.

13 Delle Monache S, Angelucci A, Sanita P, Iorio R, Bennato F, Mancini F, Gualtieri G, Colonna RC: Inhibition of angiogenesis mediated by extremely low-frequency magnetic fields (ELF-MFs). PLoS One 2013;8:e79309.

14 Hisamitsu T, Narita K, Kasahara T, Seto A, Yu Y, Asano K: Induction of apoptosis in human leukemic cells by magnetic fields. Jpn J Physiol 1997;47:307-310.

15 Yoon S, Seger R: The extracellular signal-regulated kinase: multiple substrates regulate diverse cellular functions. Growth Factors 2006;24:21-44.

-16 Bersani F, Marinelli F, Ognibene A, Matteucci A, Cecchi S, Santi S, Squarzoni S, Maraldi NM: Intramembrane protein distribution in cell cultures is affected by $50 \mathrm{~Hz}$ pulsed magnetic fields. Bioelectromagnetics 1997;18:463-469.

-17 Hu GL, Chiang H, Zeng QL, Fu YD: ELF magnetic field inhibits gap junctional intercellular communication and induces hyperphosphorylation of connexin43 in NIH3T3 cells. Bioelectromagnetics 2001;22:568-573.

18 Plotnikov A, Zehorai E, Procaccia S, Seger R: The MAPK cascades: Signaling components, nuclear roles and mechanisms of nuclear translocation. Biochim Biophys Acta 2011;1813:1619-1633.

19 Uckun FM, Kurosaki T, Jin J, Jun X, Morgan A, Takata M, Bolen J, Luben R: Exposure of B-lineage lymphoid cells to low energy electromagnetic fields stimulates Lyn kinase. J Biol Chem 1995;270:27666-27670.

20 Lindstrom E, Still M, Mattsson MO, Mild KH, Luben RA: ELF magnetic fields initiate protein tyrosine phosphorylation of the T cell receptor complex. Bioelectrochemistry 2001;53:73-78.

-21 Ke XQ, Sun WJ, Lu DQ, Fu YT, Chiang H: 50-Hz magnetic field induces EGF-receptor clustering and activates RAS. Int J Radiat Biol 2008;84:413-420. 


\section{Cellular Physiology Cell Physiol Biochem 2017;43:1533-1546 \begin{tabular}{l|l|l} 
and Biochemistry POI: 10.1159/000481977 & $\begin{array}{l}\text { C) } 2017 \text { The Author(s). Published by S. Karger AG, Basel } \\
\text { www.karger.com/cpb }\end{array}$ \\
\hline
\end{tabular} \\ Kapri-Pardes et al.: ERK1/2 Activation by ELF-MF}

-22 Thumm S, Loschinger M, Glock S, Hammerle H, Rodemann HP: Induction of cAMP-dependent protein kinase A activity in human skin fibroblasts and rat osteoblasts by extremely low-frequency electromagnetic fields. Radiat Environ Biophys 1999;38:195-199.

-23 He YL, Liu DD, Fang YJ, Zhan XQ, Yao JJ, Mei YA: Exposure to extremely low-frequency electromagnetic fields modulates $\mathrm{Na}+$ currents in rat cerebellar granule cells through increase of AA/PGE2 and EP receptormediated cAMP/PKA pathway. PLoS One 2013;8:e54376.

-24 Korzh-Sleptsova IL, Lindstrom E, Mild KH, Berglund A, Lundgren E: Low frequency MFs increased inositol 1, 4,5-trisphosphate levels in the Jurkat cell line. FEBS Lett 1995;359:151-154.

25 Zhou J, Yao G, Zhang J, Chang Z: CREB DNA binding activation by a 50-Hz magnetic field in HL60 cells is dependent on extra- and intracellular $\mathrm{Ca}(2+)$ but not PKA, PKC, ERK, or p38 MAPK. Biochem Biophys Res Commun 2002;296:1013-1018.

26 Martinez MA, Ubeda A, Cid MA, Trillo MA: The proliferative response of NB69 human neuroblastoma cells to a $50 \mathrm{~Hz}$ magnetic field is mediated by ERK1/2 signaling. Cell Physiol Biochem 2012;29:675-686.

27 Huang CY, Chang CW, Chen CR, Chuang CY, Chiang CS, Shu WY, Fan TC, Hsu IC: Extremely low-frequency electromagnetic fields cause G1 phase arrest through the activation of the ATM-Chk2-p21 pathway. PLoS One 2014;9:e104732.

-28 Flipo D, Fournier M, Benquet C, Roux P, Le Boulaire C, Pinsky C, LaBella FS, Krzystyniak K: Increased apoptosis, changes in intracellular $\mathrm{Ca} 2+$, and functional alterations in lymphocytes and macrophages after in vitro exposure to static magnetic field. J Toxicol Environ Health A 1998;54:63-76.

-29 Keshet Y, Seger R: The MAP kinase signaling cascades: a system of hundreds of components regulates a diverse array of physiological functions. Methods Mol Biol 2010;661:3-38.

-30 Piala AT, Humphreys JM, Goldsmith EJ: MAP kinase modules: the excursion model and the steps that count. Biophys J 2014;107:2006-2015.

31 Risso G, Blaustein M, Pozzi B, Mammi P, Srebrow A: Akt/PKB: one kinase, many modifications. Biochem J 2015;468:203-214.

32 Toker A, Marmiroli S: Signaling specificity in the Akt pathway in biology and disease. Adv Biol Regul 2014;55:28-38.

33 Martinez MA, Ubeda A, Moreno J, Trillo MA: Power frequency magnetic fields affect the p38 MAPK-mediated regulation of NB69 cell proliferation implication of free radicals. Int J Mol Sci 2016;17:510. DOI:10.3390/ijms17040510.

-34 Patruno A, Pesce M, Grilli A, Speranza L, Franceschelli S, De Lutiis MA, Vianale G, Costantini E, Amerio P, Muraro R, Felaco M, Reale M: mTOR activation by PI3K/Akt and ERK signaling in short ELF-EMF exposed human keratinocytes. PLoS One 2015;10:e0139644.

-35 Nie K, Henderson A: MAP kinase activation in cells exposed to a $60 \mathrm{~Hz}$ electromagnetic field. J Cell Biochem 2003;90:1197-1206.

-36 Jin M, Blank M, Goodman R: ERK1/2 phosphorylation, induced by electromagnetic fields, diminishes during neoplastic transformation. J Cell Biochem 2000;78:371-379.

-37 Sun W, Chiang H, Fu Y, Lu D, Xu Z: Effects of electromagnetic noise on the enhancement of stress-activated protein kinase(SAPK) phosphorylation induced by $50 \mathrm{~Hz}$ magnetic fields. Zhonghua Lao Dong Wei Sheng Zhi Ye Bing Za Zhi 2002;20:246-248.

38 Sun W, Yu Y, Chiang H, Fu Y, Lu D: Exposure to power-frequency magnetic fields can induce activation of P38 mitogen-activated protein kinase. Zhonghua Lao Dong Wei Sheng Zhi Ye Bing Za Zhi 2002;20:252-255.

-39 Sun W, Yu Y, Fu Y, Chiang H, Xie H, Lu D: Effects of power-frequency magnetic fields exposure on phosphorylation and enzymatic activity of stress-activated protein kinase and its upstream kinase. Zhonghua Lao Dong Wei Sheng Zhi Ye Bing Za Zhi 2002;20:256-259.

-40 Buldak RJ, Polaniak R, Buldak L, Zwirska-Korczala K, Skonieczna M, Monsiol A, Kukla M, Dulawa-Buldak A, Birkner E: Short-term exposure to $50 \mathrm{~Hz}$ ELF-EMF alters the cisplatin-induced oxidative response in AT478 murine squamous cell carcinoma cells. Bioelectromagnetics 2012;33:641-651.

41 Yung Y, Dolginov Y, Yao Z, Rubinfeld H, Michael D, Hanoch T, Roubini E, Lando Z, Zharhary D, Seger R: Detection of ERK activation by a novel monoclonal antibody. FEBS lett 1997;408:292-296.

42 Shaul YD, Seger R: The MEK/ERK cascade: From signaling specificity to diverse functions. Biochim Biophys Acta 2007;1773:1213-1226.

-43 Schuderer J, Oesch W, Felber N, Spat D, Kuster N: In vitro exposure apparatus for ELF magnetic fields. Bioelectromagnetics 2004;25:582-591. 


\section{Cellular Physiology Cell Physiol Biochem 2017;43:1533-1546 \begin{tabular}{ll|l} 
and Biochemistry & Doblished 10.1159/000481977 onlne: October 16, 2017 & $\begin{array}{l}\text { O 2017 The Author(s). Published by S. Karger AG, Basel } \\
\text { www.karger.com/cpb }\end{array}$ \\
\cline { 2 - 3 }
\end{tabular}}

Kapri-Pardes et al.: ERK1/2 Activation by ELF-MF

44 Chuderland D, Konson A, Seger R: Identification and characterization of a general nuclear translocation signal in signaling proteins. Mol Cell 2008;31:850-861.

45 Yao Z, Seger R: The molecular mechanism of MAPK/ERK inactivation. Current Genomics 2004;5:385-393.

-46 Flores K, Seger R: Stimulated nuclear import by $\beta$-like importins. F1000Prime Reports 2013;5:41. DOI: 10.12703/P12705-12741.

-47 Friedman J, Kraus S, Hauptman Y, Schiff Y, Seger R: Mechanism of short-term ERK activation by electromagnetic fields at mobile phone frequencies. Biochem J 2007;405:559-568.

-48 Erdal N, Erdal ME, Gurgul S: Lack of effect of extremely low frequency electromagnetic fields on cyclindependent kinase 4 inhibitor gene p18(INK4C) in electric energy workers. Arch Med Res 2005;36:120-123.

49 Maik-Rachline G, Seger R: The ERK cascade inhibitors: Towards overcoming resistance. Drug Resist Updat 2016;25:1-12.

50 Liedvogel M, Mouritsen H: Cryptochromes--a potential magnetoreceptor: what do we know and what do we want to know? J R Soc Interface 2010;7:S147-162.

51 Lin FJ, Song W, Meyer-Bernstein E, Naidoo N, Sehgal A: Photic signaling by cryptochrome in the Drosophila circadian system. Mol Cell Biol 2001;21:7287-7294.

-52 Fogle KJ, Parson KG, Dahm NA, Holmes TC: CRYPTOCHROME is a blue-light sensor that regulates neuronal firing rate. Science 2011;331:1409-1413. 